\title{
ТЕХНОЛОГИЯ ВЫПОЛНЕНИЯ КАДАСТРОВЫХ РАБОТ ПРИ ПОДГОТОВКЕ ТЕХНИЧЕСКОГО ПЛАНА НА ОБЪЕКТ КАПИТАЛЬНОГО СТРОИТЕЛЬСТВА
}

\section{Юлия Владимировна Шуклина}

Сибирский государственный университет геосистем и технологий, 630108, Россия, г. Новосибирск, ул. Плахотного, 10, обучающийся, e-mail: jshuklina@yandex.ru

\section{Евгений Ильич Аврунев}

Сибирский государственный университет геосистем и технологий, 630108, Россия, г. Новосибирск, ул. Плахотного, 10, кандидат технических наук, директор Института кадастра и природопользования, тел. (383)344-31-73, e-mail: kadastr204@yandex.ru

В статье, с использованием космических снимков системы «Яндекс-карты» на примере объекта капитального строительства, находящегося в Ленинском районе города Новосибирска, рассмотрен порядок выполнения полевых работ по координированию характерных точек, закрепляющих контур объекта капитального строительства и границ вновь образованного земельного участка, на котором он расположен, при подготовке графической и текстовой части технического плана.

Ключевые слова: объект капитального строительства, технический план, упорядоченный список технологических операций, государственная геодезическая сеть, опорная межевая сеть, способ полярных координат, средняя квадратическая погрешность

\section{TECHNOLOGY FOR PERFORMING CADASTRAL WORKS WHEN PREPARING A TECHNICAL PLAN FOR A CAPITAL CONSTRUCTION OBJECT}

\section{Yulia V. Shuklina}

Siberian State University of Geosystems and Technologies, 10, Plakhotnogo St., Novosibirsk, 630108, Russia, Student, e-mail: jshuklina@yandex.ru

\section{Evgeny I. Avrunev}

Siberian State University of Geosystems and Technologies, 10, Plakhotnogo St., Novosibirsk, 630108, Russia, Ph. D., Director of the Institute of Cadastre and Environmental Management, (383)344-31-73, e-mail: kadastr204@yandex.ru

In the article, using satellite images of the Yandex-maps system on the example of a capital construction object located in the Leninsky district of Novosibirsk, the procedure for performing field work to coordinate the characteristic points that fix the contour of the capital construction object and the boundaries of the newly formed land plot in which it is located, when preparing the graphic and text part of the technical plan is considered.

Keywords: capital construction object, technical plan, ordered list of technological operations, state geodetic network, reference boundary network, method of polar coordinates, average square error

Формирование производственного процесса кадастровой деятельности, итогом которого является создание Единого государственного реестра недвижимости (ЕГРН), невозможно без проведения кадастровых работ, в частности по 
отношению к объектам капитального строительства (ОКС), в результате которых осуществляется подготовка документов для государственного кадастрового учета (ГКУ).

Основным документом для ГКУ ОКС является технический план (ТП), форма и содержание которого регламентируются приказом Минэкономразвития России от 18.12.2015 № 953 [6].

Планирование технологического процесса по подготовке ТП на ОКС может быть осуществлено одним из методов составления технологических схем, а именно: упорядоченный список, блочно-логическая схема и ориентированный сетевой граф. Упорядоченный список, который применим к процессу, состоящему из небольшого числа технологических операций, с отсутствием логических связей между ними, представлен в таблице.

\section{Упорядоченный список технологических операций по подготовке технического плана}

\begin{tabular}{|c|c|}
\hline № & Название технологической операции \\
\hline \multicolumn{2}{|r|}{ 1. Составление программы работ } \\
\hline \multicolumn{2}{|r|}{ 2. Сбор и анализ исходньх данньх } \\
\hline 2.1 & $\begin{array}{l}\text { Получение необходимых данных для формирования ТП, в которые входят: } \\
\text { - проектная документация на ОН; } \\
\text { - технический паспорт ОН; } \\
\text { - поэтажные планы ОН (для многоэтажного ОН); } \\
\text { - заявка на предоставление выписки из ЕГРН об ОН; } \\
\text { - прочие документы }\end{array}$ \\
\hline 2.2 & Анализ собранных документов \\
\hline \multicolumn{2}{|r|}{ 3. Полевые работь } \\
\hline 3.1 & Описание ОН (определение его местоположения, параметров) \\
\hline 3.2 & Проектирование схемы геодезических построений \\
\hline 3.3 & $\begin{array}{l}\text { Привязка ОН на местности с использованием ГНСС-технологий и метода редуциро- } \\
\text { вания }\end{array}$ \\
\hline \multicolumn{2}{|r|}{ 4. Подготовка текстовой части ТП в соответствии с требованиями законодательства } \\
\hline \multicolumn{2}{|r|}{ 5. Подготовка графической части ТП } \\
\hline 5.1 & Проектирование схемы геодезических построений \\
\hline 5.2 & Создание схемы расположения ОН на ЗУ \\
\hline 5.3 & Формирование чертежа контура ОН \\
\hline \multicolumn{2}{|r|}{ 6. Подготовка технического плана ОН } \\
\hline
\end{tabular}

Одним из ключевых процессов формирования ТП является проведение полевых работ по координированию характерных точек, закрепляющих контур ОКСа и границ вновь образованного земельного участка (3У), на котором он расположен, что позволяет соблюсти один из принципов земельного законодательства - единство судьбы ЗУ и прочно связанных с ним ОН.

В данной статье определение координат ОКС производится одним из методов [5] - геодезическим (комбинированным, который включает в себя использование ГНСС-технологий и способа полярных координат [1]).

В качестве исходных пунктов для выполнения координирования используются пункты государственной геодезической (ГГС) и (или) опорной межевой сетей (ОМС). 
ГГС представляет собой совокупность пунктов, расположенных равномерно по всей территории, которые связаны геометрически между собой и закреплены на местности специальными центрами, обеспечивающими им долговременную сохранность [7].

ГГС создается для закрепления на всей территории страны единой системы координат, геодезического обеспечения картографирования территории РФ [4], геодезического обеспечения землеустройства и кадастра и др.

OMC - специальная геодезическая сеть, создаваемая для закрепления системы координат в территориальном образовании [8].

Для координирования характерных точек ОКСа на местности с использованием ГНСС-технологий определены координаты точек съемочного обоснования. Проект съемочного обоснования с использованием ГНСС-технологий представлен на рис. 1.

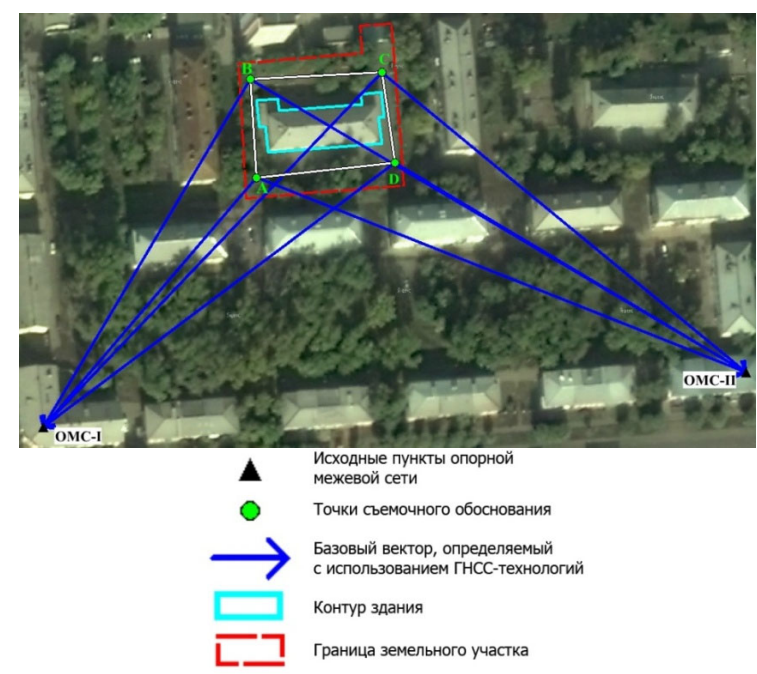

Рис. 1. Проект съемочного обоснования с использованием ГНСС-технологий

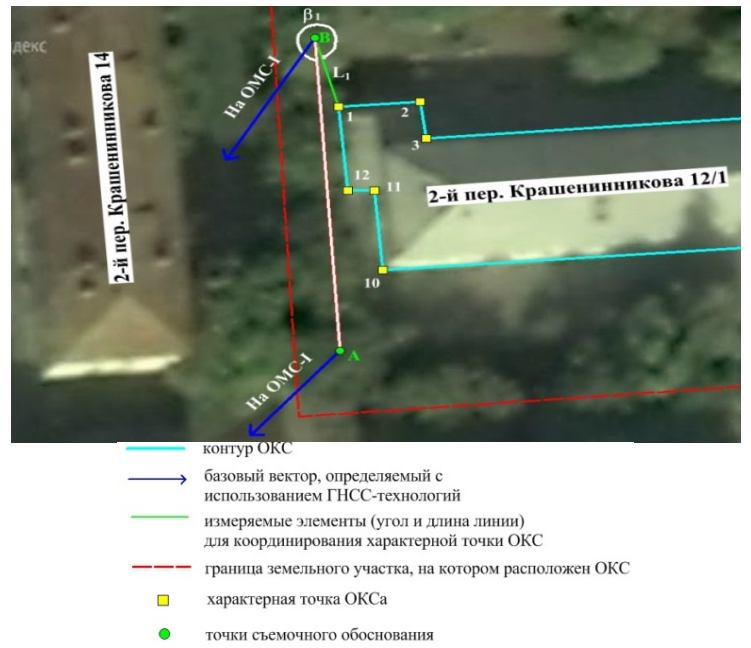

Рис. 2. Принцип координирования характерных точек ОКСа с использованием комбинированной ГНСС-технологии

Принцип координирования характерных точек ОКСа с использованием комбинированной ГНСС-технологии представлен на рис. 2.

Технологическая схема координирования ОКС комбинированным способом:

- на местности выбираются точки съемочного обоснования А и В рядом с проектным положением 1 , с учетом обеспечения оптической видимости между ними;

- после производят сеансы спутниковых измерений на базовый исходный пункт ОМС, по итогам которых вычисляют уравненные координаты точек съемочного обоснования $\mathrm{X}_{\mathrm{A}}, \mathrm{Y}_{\mathrm{A}}$ и $\mathrm{X}_{\mathrm{B}}, \mathrm{Y}_{\mathrm{B}}$. Проект съемочного обоснования представлен выше на рис. 1;

- измеряют расстояние $\mathrm{L}_{\mathrm{A}-\mathrm{B}}$ для контроля определения координат точек съемочного обоснования. Оценка точности измерений производится по формуле (1): 


$$
L_{A-B}^{\text {U3М }}-L_{A-B}^{\text {ГHCC }}=L_{A-B}^{\text {И3M }}-\sqrt{\left(X_{A}-X_{B}\right)^{2}+\left(Y_{A}-Y_{B}\right)^{2}} \leq \frac{m_{A}}{2},
$$

где $m_{A}$ - нормативно заданная средняя квадратическая ошибка положения на местности межевого знака;

$X_{A}, X_{B}, Y_{A}, Y_{B}$ - координаты точек съемочного обоснования.

- далее производится определение углового $\beta$ и линейного L коэффициентов, для определения координат характерной точки, с применением способа полярных координат, представленного на рис. 3;

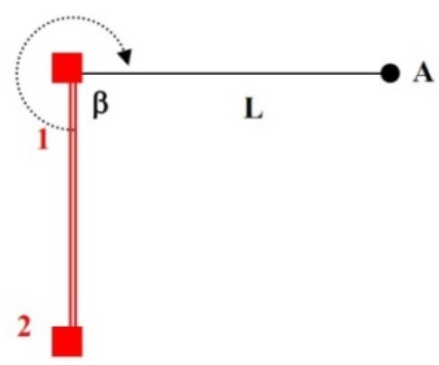

Рис. 3. Измерение углового и линейного элементов, для определения координат характерной точки способом полярных координат

- после определения координат характерной точки ОКС с нее выполняют сеанс контрольных спутниковых измерений на базовый исходный пункт ОМС;

- вывод о качестве выполненных измерений делают по разности контрольных и определенных в процессе производства координирования измерений.

Для оценки точности определения координат характерных точек контура объекта недвижимости $(\mathrm{OH})$ определяется средняя квадратическая погрешность (СКП), по формуле (2) [5]:

$$
M_{t}=\sqrt{m_{0}^{2}+m_{1}^{2}}
$$

где $M_{t}-$ СКП местоположения характерной точки относительно ближайшего пункта ОMC;

$m_{0}-$ СКП положения точки съемочного обоснования относительно ближайшего пункта ОMC;

$m_{1}-$ СКП местоположения характерной точки относительно точки съемочного обоснования.

Для определения СКП местоположения характерной точки относительно точки съемочного обоснования при использовании способа полярных координат используется формула (3): 
$m_{1}=\sqrt{m_{L}^{2}+L^{2} \frac{m_{\beta}^{2}}{\rho^{2}}}=\sqrt{0,3^{2} \mathrm{cM}+3950 \mathrm{~cm}^{2} \times \frac{2^{2}}{206265^{2}}}=\sqrt{0,4915}=0,3 \mathrm{cM}$, (3)

где $L$ - длина разбивочного элемента в сантиметрах;

$m_{L}-$ точность линейных измерений;

$m_{\beta}-$ точность угловых измерений;

$\rho=206265^{\prime \prime}$ - число секунд в одном радиане.

СКП положения точки съемочного обоснования относительно ближайшего пункта ОМС $-m_{0}$ рассчитывается как разность координат точек съемочного обоснования, полученных с использованием ГНСС-технологий, и вычисленной между ними длины линии на местности по формуле (4):

$$
\begin{array}{r}
m_{0}=L_{A-B}^{\text {ИЗМ }}-\sqrt{\left(X_{A}-X_{B}\right)^{2}+\left(Y_{A}-Y_{B}\right)^{2}}= \\
=39.38 \mathrm{~m}-\sqrt{\left((-39.46 \mathrm{M})^{2}+(2.74 \mathrm{M})^{2}\right)}=2 \mathrm{~cm} .
\end{array}
$$

Следовательно, точность определения координат характерных точек для данного ОКС будет равна:

$$
M_{t}=\sqrt{m_{0}^{2}+m_{1}^{2}}=\sqrt{0.3^{2} \mathrm{~cm}+2^{2} \mathrm{cM}}=2 \mathrm{cM} .
$$

Точность определения координат характерных точек ОКСа соответствует нормативной [5].

В том случае, когда границы земельного участка не определены, для получения на местности координат характерных точек, закрепляющих границы вновь образуемого ЗУ, строятся фигуры разбивки. Основой для их построения служат пункты геодезического обоснования. В качестве фигур разбивки используются: прямая угловая, линейная, обратная угловая засечки, способ полярных координат, комбинированный способ [1].

В данном случае, для осуществления выноса границ ЗУ на местность, применяется комбинированный способ (представленный на рис. 4), объединяющий в себе использование ГНСС-технологий и метода редуцирования.

Технологическая схема создания такой фигуры разбивки заключается в следующем:

- на местности выбираются временные точки А' и А" рядом с проектным положением А, с учетом обеспечения оптической видимости между ними;

- после производят сеансы спутниковых измерений, по итогам которых вычисляют уравненные координаты временных точек стояния $\mathrm{X}_{\mathrm{A}^{\prime}}, \mathrm{Y}_{\mathrm{A}^{\prime}}$ и $\mathrm{X}_{\mathrm{A}^{\prime \prime}}, \mathrm{Y}_{\mathrm{A}^{\prime \prime}}$; 


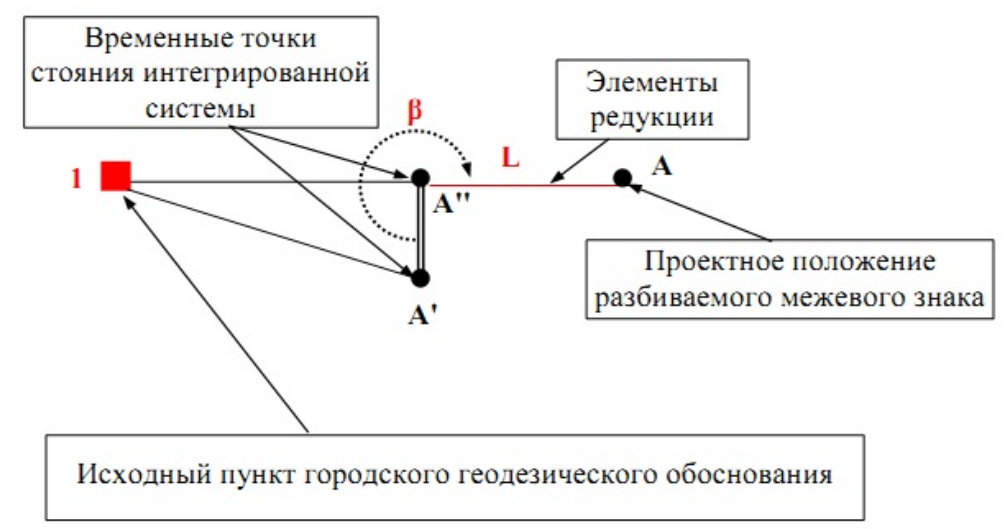

Рис. 4. Вынесение в натуру характерной точки (межевого знака) закрепляющего на местности границы вновь образованного земельного участка, на котором расположен ОКС комбинированным способом

- измеряют расстояние $\mathrm{L}_{\mathrm{A}^{\prime}-\mathrm{A}^{\prime \prime}}$ для контроля определения координат временных точек по формуле (5):

$$
L_{A^{\prime}-A^{\prime \prime}}^{\text {ИзМ }}-L_{A^{\prime}-A^{\prime \prime}}^{\text {ГHCC }}=L_{A^{\prime}-A^{\prime \prime}}^{\text {ИзM }}-\sqrt{\left(X_{A^{\prime}}-X_{A^{\prime \prime}}\right)^{2}+\left(Y_{A^{\prime}}-Y_{A^{\prime \prime}}\right)^{2}} \leq \frac{m_{A}}{2},
$$

где $m_{A}-$ нормативно заданная средняя квадратическая ошибка положения на местности межевого знака;

$X_{A^{\prime \prime}}, X_{A^{\prime}}, Y_{A^{\prime \prime}}, Y_{A^{\prime}}$ - координаты временных точек стояния инструмента.

- далее производится вычисление углового $\beta$ и линейного $\mathrm{L}$ элементов по разностям проектных и уравненных координат для выполнения редуцирования временной точки стояния инструмента в проектное положение А (с применением способа полярных координат) по формулам (6):

$$
\begin{gathered}
\beta_{\text {пр }}=\alpha_{A^{\prime \prime}-A}-\alpha_{A^{\prime \prime}-A^{\prime},} \\
\alpha_{A^{\prime \prime}-A}=\tan ^{-1} \frac{Y_{A}-Y_{A^{\prime \prime}}}{X_{A}-X_{A^{\prime \prime}}} \quad \alpha_{A^{\prime \prime}-A^{\prime}}=\tan ^{-1} \frac{Y_{A^{\prime}}-Y_{A^{\prime \prime}}}{X_{A^{\prime}}-X_{A^{\prime \prime}}}, \\
L=\sqrt{\left(X_{A^{\prime \prime}}-X_{A}\right)^{2}+\left(Y_{A^{\prime \prime}}-Y_{A}\right)^{2}}, \\
L_{A^{\prime \prime}-A}=\frac{\left(X_{A^{\prime \prime}}-X_{A}\right)}{\cos \alpha_{A^{\prime \prime} A}}, \quad L_{A^{\prime \prime}-A}=\frac{\left(Y_{A^{\prime \prime}}-Y_{A}\right)}{\sin \alpha_{A^{\prime \prime} A}},
\end{gathered}
$$

где $X_{A^{\prime \prime}}, X_{A^{\prime}}, Y_{A^{\prime \prime}}, Y_{A^{\prime}}$ - координаты временных точек стояния инструмента; $X_{A}, Y_{A}-$ проектные координаты разбиваемой точки.

Под редуцированием понимается перемещение на местности пунктов из временного положения в проектное. 
Для способа полярных координат, представляющего собой отложение от одного исходного пункта и одного дирекционного угла разбивочного угла и длины линии, точности угловых и линейных измерений определяются по формулам (7):

$$
m_{\beta}=\frac{m_{A} \times \rho}{\sqrt{2} \times L} ; m_{L}=\frac{m_{\beta}}{\rho} \cdot L=\frac{m_{\mathrm{A}}}{\sqrt{2}},
$$

где $m_{A}$ - средняя квадратическая ошибка определения характерной точки, нормативное значение для земель населенных пунктов - $0,1 \mathrm{~m}$.

Плюсы такого способа: независимость точности работ от конструкции разбивки, использование минимального количества исходных пунктов.

Минусы: отсутствие контроля качества координирования.

- после производится отложение элементов редуцирования и с полученного положения вновь выполняется сеанс спутниковых измерений на исходный пункт городского геодезического обоснования. Вывод о качестве выполненной разбивки делают по разности координат проектных значений и их спутниковых определений по формуле (8):

$$
\sqrt{\left(X^{\text {ГНCC }}-X^{\text {ПРОЕК }}\right)^{2}+\left(Y^{\text {ГНCC }}-Y^{\text {ПООЕК }}\right)^{2}} \leq m_{A} .
$$

Если критерий (8) выполняется, то такая разбивка признается удовлетворительной.

Способ комбинированных построений имеет следующие плюсы: простота в организации работ (необходимость иметь только один исходный пункт) и независимость точности измерений от конструкции фигуры разбивки.

Проект координирования характерных точек и выноса в натуру границ вновь образованного земельного участка представлен на рис. 5.

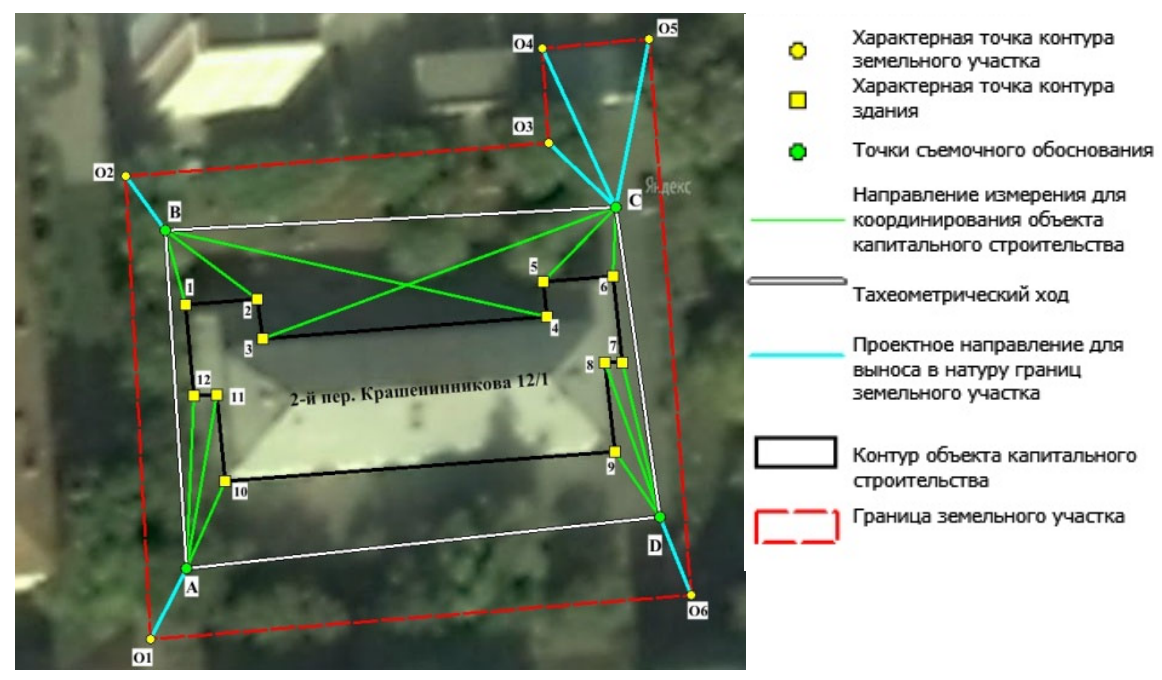

Рис. 5. Проект координирования характерных точек и выноса в натуру границ вновь образованного земельного участка 


\section{БИБЛИОГРАФИЧЕСКИЙ СПИСОК}

1. Аврунев, Е. И. Геодезическое обеспечение государственного кадастра недвижимости [Текст] / Е. И. Аврунев. - Новосибирск: СГГА, 2011. - 143 с.

2. Аврунев, Е. И. Технология и организация землеустроительных и кадастровых работ [Текст] / Е. И. Аврунев. - Новосибирск: СГГА, 2005. - 34 с.

3. Земельный кодекс Российской Федерации от 25.10.2001 № 136-Ф3 (ред. от 01.07.2020). [Электронный ресурс ] - Режим доступа: http://www.consultant.ru/document/cons_doc_LAW_33773/- Загл. с экрана.

4. О геодезии, картографии и пространственных данных и внесении изменений в отдельные законодательные акты Российской Федерации. Федеральный закон от 30 декабря 2015 года № 431-Ф3 (ред. от 03.08.2018). [Электронный ресурс] - Режим доступа: http://www.consultant.ru/document/cons_doc_LAW_191496/_-Загл. с экрана.

5. Об утверждении требований к точности и методам определения координат характерных точек границ земельного участка, требований к точности и методам определения координат характерных точек контура здания, сооружения или объекта незавершенного строительства на земельном участке, а также требований к определению площади здания, сооружения и помещения. Приказ Министерства экономического развития Российской Федерации от 1 марта 2016 г. № 90 [Электронный ресурс] - Режим доступа: http://www.consultant.ru/document/cons_doc_LAW_196699/_- Загл. с экрана.

6. Об утверждении формы технического плана и требований к его подготовке, состава содержащихся в нем сведений, а также формы декларации об объекте недвижимости, требований к ее подготовке, состава содержащихся в ней сведений. Приказ Министерства экономического развития Российской Федерации от 18 декабря 2015 г. № 953. [Электронный ресурс] Режим доступа: http://www.consultant.ru/document/cons_doc_LAW_194903/-Загл. с экрана.

7. Основные положения о государственной геодезической сети Российской Федерации [Текст] / ГКИМП (ГНТА) - 01 - 006 - 03 - Федеральная служба геодезии и картографии России. М.: 2004 г., 28 с.

8. Основные положения об опорной межевой сети ГКИНП 01-006-03 - М., Росземкадастр 2002 г., $16 \mathrm{c}$.

(С) Ю. В. Шуклина, Е. И. Аврунев, 2021 